\title{
KEY CHARACTERISTICS OF MULTICULTURAL FESTIVALS: A CRITICAL REVIEW OF THE LITERATURE
}

\author{
INSUN SUNNY LEE, ${ }^{*}$ CHARLES ARCODIA, ${ }^{1}$ and TIMOTHY JEONGLYEOL LEE $\dagger$ \\ *School of Tourism, University of Queensland, Brisbane, Australia \\ $\dagger$ Hospitality and Tourism, Ritsumeikan Asia Pacific University, Beppu City, Japan
}

\begin{abstract}
While multicultural festivals have become a significant feature of multicultural societies, offering a distinct and valuable experience for visitors, few studies have considered their role in contemporary social settings. This article outlines the key characteristics of multicultural festivals by drawing upon literature from a range of disciplines to clearly conceptualize their role. The article concludes that such festivals play a particularly significant role engendering multiculturalism in outwardly diverse social contexts. It contributes, in turn, to further comprehension of the importance of such festivals in contemporary social contexts characterized by growing ethnic diversity.
\end{abstract}

Key words: Multicultural festival; Cultural celebration; Cultural identity; Cultural expression; Social interaction

Introduction

Current and continuing trends in growing world trade, in the globalization of short-term labor, in the internationalization of education, and even in crosscultural marriages, have seen an increasing number of people migrating or sojourning internationally. In 2005, it was estimated that there were almost 191 million international migrants worldwide, an increase of 121 million people compared with 1960 (United Nations, 2005). The number of countries hosting a significant number of migrants has increased similarly during this period; while in 1960, 30 countries hosted more than 500,000 migrants each, by 2005 this number had more than doubled to 64. Not surprisingly, such trends have seen many societies become notably multicultural, with an emerging awareness of, and interest in, the importance of building well-organized multicultural societies (Parekh, 2006). Indeed, growing cultural diversity gives rise to a greater need for both developing and adapting procedures which ensure an adequate and fair treatment of all individuals irrespective of cultural differences.

As one instrument in the development and inculcation of successful multiculturalism, multicultural festivals have emerged in many social contexts worldwide. While there is considerable research and study on contemporary festivals in general, research on particular kinds of festival, including

${ }^{1}$ Address as of July 1, 2012: Department of Tourism Leisure Hotel \& Sport Management, Griffith Business School, Griffith University, QLD, Australia.

Address correspondence to Timothy Jeonglyeol Lee, Ph.D., Professor in Hospitality and Tourism, Ritsumeikan Asia Pacific University, Jumonjibaru, Beppu City, 874-8577 Japan. Tel: +81 97778 1224; Fax: +81 97778 1123; E-mail: timothylee728@yahoo.com.au 
multicultural festivals, is notably absent. The social contributions of festivals have been explored, such as social capital development (Arcodia \& Whitford, 2007), community development (Wood \& Thomas, 2006), community capacity development and support for non-tourism-related services (Moscardo, 2008), community identity and cohesion enhancement (Small, 2008), and civic pride (Wood, 2006). Given the apparent differences between various kinds of festivals in contemporary social contexts and the difficulty of generalizing findings from one kind to another, research in the area of multicultural festivals remains important. Furthermore, while it may appear that many societies have used multicultural festivals as one policy strategy for promoting social harmony, research on their success or otherwise is limited. If multicultural societies are to effectively embrace multicultural festivals with such strategic objectives, they must also consider the characteristics and content of such festivals, and how these contribute to building better multiculturalism. To evaluate multicultural festivals as an instrument in the development of multiculturalism then, research into multicultural festivals remains essential.

The aim of this article is to examine key literature relating to the areas of multiculturalism, general festivals, and cultural and community festivals. Through this analytical review of relevant literature, the key characteristics of multicultural festivals are identified, and the central roles played by multicultural festivals surmised. Recommendations for further research on the contribution of multicultural festivals within multicultural societies are also suggested.

\section{Multiculturalism}

Understanding the basic concept of multiculturalism and useful strategies for building a successful multicultural society is essential to building a knowledge platform from which to proceed. As the mobility of people between countries in the past few decades has increased, the term multiculturalism has become popular in many social contexts. However, the term has no fixed definition, whether in political debate or cultural or scholarly discourse. In a descriptive capacity multiculturalism is often used to describe social situations overtly characterized by a multitude of ethnic groups, cultures, religions, and languages (Chadwych, 2009; Chin, 1992). Yet, this definition lacks the necessary clarity to fully convey the concept's complexities and application in contemporary social contexts. Hence, Runblom (1994), for instance, defined multiculturalism as "an ideal situation of peaceful coexistence between individuals or groups of diverse origin" (p. 624). Such a pragmatic definition remains more comprehensive and representative of the term in the broadest sense, with its emphasis on peaceful coexistence of individuals or groups of diverse origin within specific boundaries.

Many recommendations for effective multicultural policies have been suggested in previous research. Berry, Phinney, Sam, and Vedder (2006) suggest governments provide support for minorities to stem and prevent cultural loss, and to promote ethnic identity. These authors also suggest governments develop policies and programs for the dominant population in support of multiculturalism. Similarly, Kosic, Mannetti, and Sam (2005) suggest using implementation programs to alter dominant population attitudes toward minorities to help reduce interethnic conflict. Approaches involving both educational, as well as judicial measures can be considered viable directions in terms of such programs.

The contact theory formalized by Allport (1954) suggests negative attitudes and prejudices held by one ethnic group toward another can be reduced through intergroup contact. When individuals of two groups come into positive, personal, and cooperative contact with one another, they become acquainted and as a consequence, prejudices are reduced or potentially eliminated. Integral to this is that the interaction needs to take place between individuals of equal status with common goals, intergroup cooperation, and with the support of authorities, laws, and customs (Allport, 1954). More recently, Pettigrew $(1997,1998)$ reformed the contact theory by adding an additional condition-friendship potential-for optimal contact. Under these conditions, mutual attitudes and interaction will become more positive, for instance, via an emerging recognition of similarities (Pettigrew, 1997, 1998), thus aiding acculturation. Moreover, the importance of social support also acquires emphasis through coping strategies and emerging 
acculturation. In short, new skills and information for both mainstream and migrant cultures and society are required.

In light of the suggestions in precedent literature, multicultural festivals have emerged in many societies worldwide not only to encourage minorities to maintain their origin culture, but also to increase contact between the dominant population and minority group members in order that mutually negative attitudes and prejudices be reduced, and a well-organized multicultural society built.

\section{Multicultural Festivals}

McClinchey (2008) defines a multicultural festival as a place for public celebration showcasing the ethnic culture of local communities resettled due to migration. However, this definition appears to focus on their showcase nature without adequately considering their meanings. In contrast, Duffy (2005) defined multicultural festivals more specifically as places for ongoing dialogue and negotiation within communities, as individuals as well as groups attempt to define meaningful concepts of identity and belonging along with notions of exclusion. That said, while Duffy's definition of multicultural festival covers a range of meanings, such meanings can be more varied still. Based on a combination of McClinchey's and Duffy's definitions of multicultural festivals therefore, such festivals can best be defined as public, multicultural themed celebrations at which multi-ethnic people-including both ethnic minorities and members of the dominant population-have an extraordinary as well as mutually beneficial experience.

While multicultural festivals are held in many cities to promote social harmony and integration, there appears to be very little research into their role. Due to both the increasing number of multicultural festivals, along with this lack of knowledge and concerted research about them, there is a clear demand to understand the role they do and can play, and in turn refine their management. Literature that remains essential as a starting point includes clusters dealing with the key characteristics of general festivals, as well as those considering cultural and community festivals in terms of cultural celebration, identity, expression, and social interaction.

\section{Cultural Celebration}

Celebration can be defined as a "performance entailing the dramatic presentation of cultural symbols," "public, with no social exclusion," or as "participatory entertainment" (Manning, 1983, p. 4). Most scholars argue that celebrations seek to focus people's attention and intentions in a positive way. Hence, the resulting celebratory acts and/or products create a time and place for what a particular individual or cultural community values. Given the four key characteristics of celebration as defined by Arcodia and Whitford (2007) — namely performance of cultural symbols, entertainment, activities undertaken in a public place, and community participation - many agree that the most common and encompassing type of public community celebration remains the festival.

However, alternate definitions further confirm celebration as one of the core aspects of festivals. As a result, Janiskee defined festivals as "formal periods or programs of pleasurable activities, entertainment, or events having a festive character and publicly celebrating some concept, happening or fact" (cited in De Bres \& Davis, 2001, p. 329). Similarly, the United Kingdom Policy Studies Institute asserts that "a festival was traditionally a time of celebration and recuperation which often followed a period of hard physical labor, sowing or harvesting of crops, for example. The essential feature of these festivals was the celebration or reaffirmation of community or culture. The artistic content of such events was variable and many had a religious or ritualistic aspect, but music, dance and drama were important features of the celebration" (cited in Bowdin \& Williams, 2005, p. 466).

In addition, Hilbers (2006) further defined the range of activities that can comprise community celebrations. According to this author, these can include the creation of art products by artists, performances, art and craft activities, music, dance, food, commercial stalls, markets, fireworks, parades, fundraising, displays, show and tell activities, demonstrations, show bags, speakers, competitions, talent quests, environmental activities, bonfires, and publications. This researcher further claimed that community celebrations have one or more themes, such as enjoyment and fun or relief from everyday life; bringing people together and creating a sense 
of community; building community in general; showcasing people, the arts, cultural traditions, and community assets; educating through providing opportunities for skill development or personal transformation; creative expression; social healing (e.g., Aboriginal reconciliation); valuing diversity by providing exposure to a range of ethnic cultures and challenging racist values; social action, in particular advocacy for the most disadvantaged within the community; and lastly, the interconnection between self, community, spirit, and the earth.

In light of these celebratory themes, such festivals allow people, regardless of culture or status, to participate in an occasion that generates a feeling of goodwill and community (Salamone, 2000). Not surprisingly, such festivals hold the potential to strengthen communal ties and unite people (Earls, 1993), as well as foster belonging and sharing among the family, social group, community, or wider nation (Getz, 2007). Furthermore, they not only facilitate the development of contemporary cultural identity, but enhance the wellbeing of the community by, among other things, providing an "opportunity to break away from daily routines and ... socialize with family and friends within the larger community" (Earls, 1993, p. 32).

Rokam (2005) similarly supports the idea that the celebration of festivals provides a community with a sense of common identity by creating feelings of shared history. In other words, such celebrations provide a common platform where individual members of a community share a mutual sense of joy with one another. For Rokam (2005), cultural festivals emerged to be a common platform for individuals to come together and display a sociocultural ethos. Hence, key attractions usually include ritual performances, cultural programs, games and sports events, and so on. Furthermore, cultural festivals or multicultural festivals for minority groups in particular, normally represent the cultural specialties providing sustenance to such groups and ultimately promote the continuation of custom, tradition, and culture. These provide a common platform to the community, therefore bringing manifold aspects and diverse features of minorities' lifestyle and unifying them. Moreover, in his study on the role of festivals as vehicles for social change, Sharpe (2008) argued that festivals are social gatherings whose organizers often have liberalizing aims and intentions, and attempt to posit their festival as an instrument of social change. Sharpe (2008) similarly considers personal inspiration and transformation as social changes possible through festival attendance, and Arcodia and Whitford (2007) argue that a focus on celebration in festivals shows their clear ties to the development of social capital.

Within this perspective, multicultural festivals provide minority groups with a place for cultural community celebration, drawing on people's memories and experiences of their birthplace, and reaffirming community and culture. As Arcodia and Whitford (2007) point out, multicultural festivals in Australia that celebrate the character and richness of cultural diversity within the society are successful models of multicultural policy. In addition however, and in terms of their educational aspects, multicultural festivals play a different role to different visitors. While many migrants see such festivals as an opportunity to educate younger generations about their traditions, beliefs, and practices, many in the dominant population see them as opportunities to learn about other communities' and cultures.

\section{Cultural Identity and Expression}

While cultural expression and preservation form important parts of a minority culture's identity, such groups still struggle to collectively express, share, and thus preserve their cultural heritage within a system and social fabric which favors the dominant population and culture. Hence, Goodman (1999) defines cultural participation and expression as a universal imperative. The fact remains that the celebration and expression of culture allows minority cultural groups to preserve their culture, both as a collective group and as one part of an individual's identity, and to ensure its continuation from one generation to another (Lentz, 2001; OsterlundPotzsch, 2004). Indeed, for Guss (2000), the basic goal of cultural expression is the celebration and preservation of culture. This expression, whether public or private, is commonly shared among cultural group members, thus allowing culture to be maintained and preserved via group interaction and practice (Fong, 2004; Schiavoni, 1991).

Cultural expression in its public form ,therefore, is a key component of cultural preservation for 
ethnic minorities (Bailey \& Oetzel, 2004; Fong, 2004). Day to day cultural expression is normally limited by the structure of the dominant society, which favors the expression and, thus, maintenance of the dominant group culture. In our daily lives the dominant population are "living out" their culture; it is subconsciously and implicitly practiced throughout daily life (Bailey \& Oetzel, 2004; Chiu $\&$ Hong, 2006). In contradistinction, ethnic minorities rely on an allocation of space, resources, and time for public cultural celebrations, as well as private opportunities, such as family parties (Dyke \& Dyke, 2002). It has been highlighted, therefore, that consideration needs to be given to cultural groups to enhance the allocation of space, and thus, opportunity for public cultural expression.

Researchers assert that festivals provide an opportunity for new and emerging communities to strengthen their sense of identity and distinctiveness, and thus, their capacity to express their own cultures (Falassi, 1987; Hilbers, 2006). In this sense, multicultural festivals may also play an important role for minority group members by offering them a means to cultural participation and expression. The Australian Government, for instance, has mainly concentrated on cultural expression as public spectacles, with multicultural festivals employed in particular as a major form of public cultural celebration (Multicultural Affairs Queensland, 2006). Moreover, Osterlund-Potzsch (2004) goes further to suggest that public festivals, such as multicultural festivals, are the one ethnic arena in which there exists a readiness for ethnic communication, and where ethnic expression is to be expected.

Multicultural festivals, as a public display, can allow ethnic minorities to reestablish ties with their homeland and culture through shared expression and collaboration with members of the same ethnicity, central to the sustenance of each member's cultural identity. They clearly also provide opportunities for various cultural groups to support one another, and share in their struggle as a minority group in a mainstream culture (Bailey \& Oetzel, 2004; Fong, 2004; Lentz, 2001). Therefore, while daily cultural expression supported by the infrastructure of a society holds obvious advantages in comparison to infrequent public displays of culture, these public displays are still significant to ethnic minorities in the sustaining of their cultural identities. Furthermore, by expressing their own culture and strengthening their identity, minority groups feel both comfortable and secure within a multicultural society. Working together on a common activity, such as a public performance, can also foster dialogue within groups themselves about the nature of their cultural identity.

Multicultural festivals offer a variety of programs, such as folk dance and ethnic music, and the preparation of ethnic food. Such traditions are of great importance to ethnic minorities as a positive means of profiling the minority to the general public, while simultaneously providing an opportunity for mobilization to the in-group (OsterlundPotzsch, 2004). In fact, genres such as folk dance and ethnic music have become the main format to present ethnic culture, given traditional song and music usually hold a strong sentimental value. Osterlund-Potzsch (2004) further emphasizes that ethnic cooking and food items also represent ethnicity. Through their programs, multicultural festivals offer opportunities to express the minority culture to the public; in this way, such festivals not only celebrate and preserve culture, but also foster cultural acceptance within the mainstream community, generate community acceptance of cultural diversity, and reinforce the society as a multicultural one in the collective mind of the community (Jupp, 1996). As aforementioned, it remains important to note that multicultural festivals not only provide minority groups with the opportunity to express their culture, but also an opportunity for the dominant population to view other cultures (Picard \& Robinson, 2006).

\section{Social Interaction}

All festivals seem to involve and engender some form of social concentration and connectivity. In its simplest form, this occurs at an individual level when at least two individuals meet and interact. At a macrolevel, this occurs when one or several groups of individuals meet in a single time-space frame (Picard \& Robinson, 2006). Group is seen here to include, on the one hand, in a necessarily broad sense, highly structured social entities based on established kinship, friendship, or professional networks. On the other hand, however, group also includes much looser social entities, often without 
a strong internal structure, and based on a form of shared reference to common interests, problems, feelings of belonging, residence, ethnicity, race, social status, and so on. The meeting of members of such groups, whatever their motivation or the criteria used to define group inclusion, is a necessary formal principle of any festival. Not surprisingly, Kuutma (1998) states that cultural festivals present expressive forms of culture where social interaction is instrumental. Essentially, festivals provide the scenery for the interplay of tradition and innovation in communicative social life. The created communicative situation reflects the shared experience of the group, promotes social revitalization, and celebrates ethnic identity in a context of cultural expression.

In terms of multicultural festivals in particular, all visitors, whether members of a minority group or of the dominant population, interact as visitors, exhibitors, and performers, with such interactions of benefit to both the minority and dominant population in terms of breaking prejudices and stereotypes. As shown in Cho's (2006) study of South Korea, $44 \%$ of minority group member respondents do not interact with the dominant population, with one exception being with school teachers. Members of the dominant population and minority group members hardly meet and interact with one another in everyday life therefore encouraging prejudice and stereotypes. According to Stephan's (1987) contact hypothesis, which claims that patterns of prejudice and stereotype can be broken by direct intergroup contact, the interactions possible at multicultural festivals can facilitate the end of prejudice and the promotion of social harmony. In addition, multicultural festivals appear to provide opportunities for not only interaction between minorities and the dominant population, but also between minority group members themselves. As Kuutma (1998) states, a multicultural festival can be seen as a place for minority group members to meet, to communicate with people with the same culture, and to relieve their nostalgia for their homeland.

\section{Discussion}

This article has suggested that multicultural festivals include three key characteristics: cultural celebration, cultural identity and expression, and social interaction. These three core features of multicultural festivals reveal the potential roles multicultural festivals can play in developing successful multiculturalism. Firstly, multicultural festivals appear to provide minority groups with a place for cultural community celebration, drawing on people's memories and experiences of their birthplace, and reaffirming community and culture. They also provide opportunities for members of minority groups to have extraordinary experiences; given the place for ethnic minorities to celebrate their origin culture is limited. Hence, multicultural festivals help ethnic minorities deal with the stress of daily life, relieving their nostalgia for their homeland and making them more comfortable in terms of the mainstream culture.

Secondly, multicultural festivals offer ethnic minorities a place for cultural participation, as well as cultural expression. For ethnic minorities, it remains difficult to express their culture of origin in daily life, hence, their participation and expression at multicultural festivals is both extraordinary and valuable. It has been argued that the opportunities and facilities to maintain ethnic minorities' culture of origin are necessary to lessen stress among ethnic minorities, and to provide a necessary balance for an effective multicultural society (Berry et al., 2006). Hence, multicultural festivals contribute to the development of successful multiculturalism, allowing ethnic minorities the opportunity to preserve their culture and ensure its continuation from one generation to another, while at the same time alleviating stress.

Lastly, multicultural festivals allow both ethnic minorities and the dominant population the opportunity to socialize with family and friends. Such festivals provide a place for interaction between ethnic minorities and the dominant population, and between ethnic minority group members themselves. Such interaction between ethnic minorities and the dominant population can break prejudices, as well as promote social harmony. Furthermore, as ethnic minorities can meet with and communicate with other members of the same culture, multicultural festivals provide them with opportunities to share information and make new friends, and hence, live among the dominant culture more easily. In turn, it can be argued that multicultural festivals play a significant role in multicultural societies in 
terms of the development of successful multiculturalism. The summary of these three characteristics and the roles of multicultural festivals are presented in Table 1.

\section{Conclusion and Implications}

This article has critically examined key literature relevant to the characteristics and role of multicultural festivals in multicultural societies, covering both the characteristics of general festivals, and those of cultural and community festivals. Through this review, the characteristics of multicultural festivals were identified, and it was suggested multicultural festivals play a significant role in the development and engendering of successful multiculturalism. The article provides an analytical and timely perspective on the role of multicultural festivals in building better multicultural societies. In short, a better understanding of visitor experiences at multicultural festivals and the benefits gained will encourage society, industry, and governments to better consider multicultural festivals in their strategic promotion of multiculturalism. If multicultural festivals enable a coming together of the dominant population and ethnic minorities, and assist ethnic minorities in their relationship to mainstream culture, society overall can obtain benefits in terms of both culture and economy.

In aiming to establish a solid theoretical framework for the role of multicultural festivals in multicultural societies, this study has considered only secondary data. The article encourages future research and initiates directions for more comprehensive study in the area in the future. There remains a need to develop more empirical research on the role of multicultural festivals, with primary data on the experiences, benefits, levels of satisfaction, impressions, and meaning obtained by participants of multicultural festivals. Investigation may include the experiences and benefits visitors acquire from a visit to multicultural festivals, and how these experiences and benefits can contribute to building a better multicultural society.

There is also a need to compare the different roles played by multicultural festivals for both ethnic minorities and members of the dominant population. It is considered important to understand the differences in order to organize and manage multicultural festivals to be relevant to both to the dominant population and ethnic minority groups. It is also interesting to compare the roles of multicultural festivals played in different societies, one in a society in transit to becoming a multicultural society, for example, South Korea, and one in a society in which multiculturalism is well established, for example, Australia. The role of multicultural festivals may differ in different societies - multicultural festivals in a society in transit to becoming a multicultural society may be held to promote social harmony between cultures, while those held in a society in which multiculturalism is well established may

Table 1

Summary of Characteristics and Roles of Multicultural Festivals

Roles

Characteristics Minority Groups Dominant Population

Cultural Reaffirm community and culture.

celebration Educate younger generations about their traditions and beliefs.

Cultural identity Reestablish ties with their homeland and culture. and expression Sustain their cultural identities.

Feel comfortable and secure within a multicultural society by strengthening their identity.
Celebrate the richness of cultural diversity within the society.

Learn about other communities' and cultures.

View other cultures.

Foster cultural acceptance within the mainstream community.

Generate community acceptance of cultural diversity.

Reinforce the society as a multicultural one in the collective mind of the community.

Break prejudice.

Promote social harmony. 
aim to celebrate cultural diversity. Understanding the different roles of multicultural festivals for different groups of festival attendees in different societies helps all key stakeholders to guide festival management to organize festivals that meet the needs and wants of different groups in different societies. Such investigation remains essential, given multicultural festival visitor experiences and benefits can be a barometer for the development of multiculturalism, and may indeed assist in enhancing social integration. Identifying what experience leads to which benefit may also assist multicultural festival organizers and the public sector achieve the foundational aim of multicultural festivals, namely a greater understanding of different cultures and the promotion and facilitation of harmony between cultures.

\section{References}

Allport, G. W. (1954). The nature of prejudice. Cambridge: Addison-Wesley.

Arcodia, C., \& Whitford, M. (2007). Festival attendance and the development of social capital. Journal of Convention and Event Tourism, 8(2), 1-18.

Bailey, C., \& Oetzel, J. (2004). Tighten me up: Reflecting and maintaining ethnic identity through daily interactions in an African American-owned beauty salon. In M. Fong \& R. Chuang (Eds.), Communicating ethnic and cultural identity. US: Rowman and Littlefield.

Berry, J. W., Phinney, J. S., Sam, D. L., \& Vedder, P. (2006). Immigrant youth: Acculturation, identity, and adaptation. Applied Psychology, 55(3), 303-332.

Bowdin, G., \& Williams, M. (2005). An investigation into the effectiveness of arts festivals evaluation. Paper presented at the International Event Management Summit, Sydney.

Chadwych, H. (2009). Webster's third new international dictionary, unabridged (online edition). Retrieved August 8, 2009, from http://collections.chadwyck.co.uk/ home/home_mwd.jsp?template=basic.htx\&content $=$ frameset.htx

Chin, D. (1992). Multiculturalism and its masks: The art of identity politics. Performing Arts Journal, 14(1), 1-15.

Chiu, C. Y., \& Hong, Y. Y. (2006). Social psychology of culture. New York: Psychology Press.

Cho, S. K. (2006). Foreign workers' language problems and plan. In New Korean life. Seoul, South Korea: The National Institute of the Korean Language.

De Bres, K., \& Davis, J. (2001). Celebrating group and place identity: A case study of a new regional festival. Tourism Grographies, 3(3), 326-337.

Duffy, M. (2005). Performing identity within a multicultural framework. Social \& Cultural Geography, 6(5), 677-692.

Dyke, C., \& Dyke, C. (2002). Identities: The dynamical dimensions of diversity. In P. Alperson (Ed.), Diversity and community: An interdisciplinary reader. Malden, MA: Blackwell Publishers.

Earls, Z. (1993). First night celebration: Building community through the arts. Festival Management \& Event Tourism, 1, 32-33.

Falassi, A. (1987). Festival: Definition and morphology. In A. Falassi (Ed.), Time out of time. Albuquerque, NM: University of New Mexico Press.

Fong, M. (2004). Multiple dimensions of identity. In M. Fong \& R. Chuang (Eds.), Communicating ethnic and cultural identity. US: Rowman and Littlefield.

Getz, D. (2007). Event studies: Theory, research and policy for planned events. Oxford: Butterworth-Heinemann.

Goodman, J. (1999). Come together: The Woodford-Maleny festival. Arena Magazine, 38, 39-40.

Guss, D. M. (2000). The festive state: Race, ethnicity, and nationalism as cultural performance. Los Angeles: University of California Press.

Hilbers, J. (2006). Celebrations for personal and collective health and wellbeing. Sydney: University of Technology, Sydney.

Jupp, J. (1996). Understanding Australian multiculturalism. Canberra: Australian Government Publishing Service.

Kosic, A., Mannetti, L., \& Sam, D. L. (2005). The role of majority attitudes towards out-group in the perception of the acculturation strategies of immigrants. International Journal of Intercultural Relations, 29, 273-288.

Kuutma, K. (1998). Festival as communicative performance and celebration of ethnicity. Folklore, 7, 76-86.

Lentz, C. (2001). Local culture in the national arena: The politics of cultural festivals in Ghana. African Studies Review, 44(3), 47-72.

Manning, F. (1983). The celebration of society: Perspectives on contemporary cultural performance. Bowling Green, $\mathrm{OH}$ : Bowling Green University Popular Press.

McClinchey, K. A. (2008). Urban ethnic festivals, neighbourhoods, and the multiple realities of marketing place. Journal of Travel and Tourism Marketing, 25(3), 251-264.

Moscardo, G. (2008). Analysing the role of festivals and events in regional development. Event Management, $11(1 / 2), 23-32$.

Multicultural Affairs Queensland (2006). Multicultural highlights: 2005-2006 report. Brisbane: The Queensland Government.

Osterlund-Potzsch, S. (2004). Communicating ethnic heritage: Swedish-speaking Finn descendants in North America. In U. Kockel \& M. N. Craith (Eds.), Communicating cultures (pp. 14-41). Munster: Lit.

Parekh, B. (2006). Rethinking multiculturalism: Cultural diversity and political theory. (2nd ed.) New York: Palgrave Macmillan.

Pettigrew, T. F. (1997). Generalized intergroup contact effects on prejudice. Personality and Social Psychology Bulletin, 23(2), 173-185.

Pettigrew, T. F. (1998). Intergroup contact theory. Annual Review of Psychology, 49, 65-85. 
Picard, D., \& Robinson, W. P. (2006). Remaking worlds: Festivals, tourism and change. In D. Picard \& W. P. Robinson (Eds.), Festivals, tourism and social change: Remaking worlds (pp. 1-31). Clevedon, UK: Channel View Publications.

Rokam, N. T. (2005). Emerging religious identities of Arunachal Pradesh: A study of Nyishi tribe. New Delhi: Mittal Publications.

Runblom, H. (1994). Swedish multiculturalism in a comparative European perspective. Sociological Forum, 9(4), 623-640.

Salamone, F. (2000). Society, culture, leisure and play: An anthropological reference. Maryland: University Press of America.

Schiavoni, F. (1991). The case for linguistic pluralism. In D. Goodman, D. J. O’Hearn, \& C. Wallace-Crabbe (Eds.), Multicultural Australia: The challenges of change. Newham, Vic: Scribe.

Sharpe, E. K. (2008). Festivals and social change:
Intersections of pleasure and politics at a community music festival. Leisure Sciences, 30, 217-234.

Small, K. (2008). Social dimensions of community festivals: An application of factor analysis in the development of the social impact perception (SIP) scale. Event Management, 11(1/2), 45-55.

Stephan, W. (1987). The contact hypothesis in intergroup relations. Review of Personality and Social Psychology, 9, 41-67.

United Nations (2005). Trends in total migrant stock: The 2005 revision. New York: Population Division, Department of Economic and Social Affairs, United Nations.

Wood, E. H. (2006). Measuring the social impacts of local authority events: A pilot study for a civic pride scale. International Journal of Nonprofit and Voluntary Sector marketing, 11, 165-179.

Wood, E. H., \& Thomas, R. (2006). Measuring cultural values: The case of residents' attitudes at the Saltaire festival. Tourism Economics, 12(1), 137-145. 